\title{
Diabetic Complications and Associated Factors: A 5-Year Facility-Based Retrospective Study at a Tertiary Hospital in Rwanda
}

\author{
Angelique Iradukunda (D) \\ Shallon Kembabazi (iD) \\ Nelson Ssewante (iD) \\ Andrew Kazibwe (iD ${ }^{2}$ \\ Jean Damascene \\ Kabakambira ${ }^{3}$ \\ 'School of Medicine, College of Health \\ Sciences, Makerere University, Kampala, \\ Uganda; ${ }^{2}$ Department of Internal \\ Medicine, College of Health Sciences, \\ Makerere University, Kampala, Uganda; \\ ${ }^{3}$ Department of Internal Medicine, \\ University Teaching Hospital of Kigali, \\ Kigali, Rwanda
}

\begin{abstract}
Introduction: Diabetes mellitus (DM) is a chronic metabolic disorder characterized by hyperglycemia resulting from defects in insulin production, insulin action, or both. Despite advances in DM diagnosis and management, the incidence of DM-related complications remains high. This study aimed to determine patterns of common complications and associated factors among hospitalized patients in Rwanda.
\end{abstract}

Methods: A cross-sectional study, with retrospective chart review, was conducted at CHUK from July to August, 2021. Charts for DM patients admitted from January 2016 to December 2020 were considered while those inaccessible at the time of data collection were excluded. Linear regression model was used to assess the relationship between dependent and independent variables with a $\mathrm{p}<0.05$ considered statistically significant.

Results: A total of 246 charts were reviewed. The median age was 56 years (IQR: 14-90). More than half of participants $(\mathrm{n}=135 ; 54.9 \%)$ were females; majority from the Central region $(\mathrm{n}=138 ; 56.7 \%)$. Recorded DM risk factors included alcohol intake $(\mathrm{n}=81 ; 48.5 \%)$; smoking ( $\mathrm{n}=40 ; 24.2 \%)$, obesity $(\mathrm{n}=43 ; 52.4 \%)$, and family history of DM ( $\mathrm{n}=27$; $56.3 \%)$. Majority $(\mathrm{n}=153 ; 84.5 \%)$ had type $2 \mathrm{DM}$ and $(\mathrm{n}=147 ; 69 \%)$ had known their diagnosis for at least 6 years. Hypertension $(\mathrm{n}=124,50.4 \%)$, acute hyperglycemic state $(\mathrm{n}=$ $59,24 \%)$, nephropathy $(\mathrm{n}=58,23.6 \%)$, and stroke $(\mathrm{n}=38,15.4 \%)$ were frequently reported complications. Nearly all participants $(n=81,95.2 \%)$ with complications had poor glycemic control. Alcohol intake, age $\geq 45$ years, and T1DM were associated with higher odds of DM complications $(\mathrm{aOR}=8,95 \% \mathrm{CI}=2-32.6, \mathrm{p}=0.003, \mathrm{aOR}=6.2,95 \% \mathrm{CI}=1.4-27.6, \mathrm{p}=$ 0.016 and $\mathrm{aOR}=14.1,95 \% \mathrm{CI}=1.2-161.5, \mathrm{p}=0.034$, respectively). Duration of DM $(\mathrm{p}=$ 0.001 ) was significant at bivariate analysis.

Conclusion: DM complications were prevalent among the studied population with poor glycemic control mainly influenced by alcohol consumption and duration of DM. Expansion of integrated DM and hypertension screening services to lower-level centers is needed to reduce the associated morbidity and mortality.

Keywords: diabetes mellitus, microvascular, macrovascular, complications, noncommunicable disease

\section{Introduction}

Diabetes mellitus (DM) is a chronic metabolic disorder characterized by high blood sugar resulting from defects in insulin production, insulin action, or both. ${ }^{1}$ Type 2 DM (T2DM) accounts for over 75\% of all cases globally; and it's associated with modifiable risk factors such as obesity, unhealthy dietary habits, sedentary life style, alcohol consumption and cigarette smoking. ${ }^{2-5} \mathrm{DM}$ is characterized by
Correspondence: Angelique Iradukunda School of Medicine, College of Health Sciences, Makerere University, Kampala, Uganda

Email iradangelique3@gmail.com 
hyperglycemia, dyslipidemia and disordered immune function that result in micro and macrovascular complications such as peripheral neuropathy, retinopathy, nephropathy, peripheral vascular disease, stroke and coronary artery disease ${ }^{6-8}$ Despite advances in DM diagnosis, therapies and supportive management, these complications account for a growing burden of morbidity, and mortality.

DM is one of the fastest growing global health emergencies with over 463 million people (20-79 years) estimated to be living with, and another four million to have died from DM in 2019. ${ }^{9}$ It is estimated that 629 million people will have DM by $2045 .{ }^{10}$ Over $75 \%$ of individuals with DM live in low- and middle-income countries; and the burden of DM in Sub-Saharan Africa (SSA) increased by $126.4 \%$ between 1990 and 2017, due to increased sedentary lifestyles (as a result of urbanization and population growth), unhealthy diets, and ageing. ${ }^{11} \mathrm{DM}$ is a major cause of blindness, renal failure, cardiovascular disease, stroke and lower limb amputation. ${ }^{2}$ About 2.8\% of Rwanda's 12.95 million people were estimated to be living with DM by $2016 .{ }^{12}$

DM in SSA is associated with high morbidity and mortality due to late diagnosis and suboptimal care to avert complications. ${ }^{13}$ This is expected to compound the burden of endemic communicable diseases such as HIV and Tuberculosis. With DM affecting mostly the middleaged population, it imposes serious economic and social implications especially in the developing world. ${ }^{14}$ People living with diabetes spend twice on medical costs as high as those without DM. ${ }^{15}$ The World Health Organization (WHO) recommends simple life style modification as an effective measure to reduce morbidity and mortality associated with DM. ${ }^{2}$

Despite universal healthcare coverage through community-based health insurance scheme and use of health technologies to increase access to DM diagnosis and care in Rwanda, knowledge of DM, risk factors and complications is still limited especially in rural areas. Yet still, there seems to be a growing prevalence of DM modifiable risk factors, with recent statistics showing that up to $17.5 \%$ and $3.3 \%$ of the country's population are overweight and obese respectively; and at least $13.6 \%$ are physically inactive. ${ }^{14}$ According to Rudasingwa et al in their study conducted about a decade ago, there was a growing burden of DM complications in Rwanda calling for a policy shift to prevention of DM and its complications. ${ }^{16}$ However, their study findings were preliminary and were limited by lack of biochemical correlation with the reported complications. Since their publication, self-monitoring interventions (such as the Kir'App) have been implemented with limited knowledge of their impacts on DM progression. As an update of the current situation in Rwanda, we conducted an assessment of the patterns of DM complications and the associated factors over the past five years so as to contribute to the broad knowledge and SDG3 of reducing mortality from DM.

\section{Methods}

\section{Study Design}

This was a cross-sectional study with retrospective chart review, conducted at University Teaching Hospital of Kigali (CHUK), archives department from July to August, 2021.

\section{Selection Criteria}

We considered all charts for DM patients admitted at CHUK, Internal Medicine wards from January 2016 to December 2020 for review. Patients' charts across all age groups were eligible for review. DM patients who may have been admitted for other reasons on wards other than internal medicine department including pediatric patients were not included in this review. Additionally, charts which were inaccessible during the time this study was conducted were excluded.

\section{Sample Size and Sampling Procedure}

From 2016 to 2020, CHUK admitted a total of 667 patients with a diagnosis of DM. To access their medical records, patient ID numbers were obtained from the respective internal medicine wards. These ID numbers were fed into the Open Clinic $\mathrm{GA}^{\circledR}$ data management system to retrieve their respective archive numbers. Finally, using the archive numbers patients' charts were located consecutively from shelves in the Archives.

\section{Data Collection and Analysis}

An online data collection tool was designed using Kobo Toolbox ${ }^{\circledR}$ software. The tool captured data on exposure variables: social demographic characteristics, DM type, duration of DM, level of glycemic control at time of admission; and outcome variables: Hypertension (HTN), Diabetic Ketoacidosis (DKA), Diabetic Nephropathy (DN), Stroke, Diabetic Retinopathy (DR), and Diabetic Peripheral Neuropathy (DPN). Fully completed entries were downloaded from the cloud, were cleaned and coded using Microsoft Excel 2016 and then analyzed using STATA 15 software. Numerical data were 

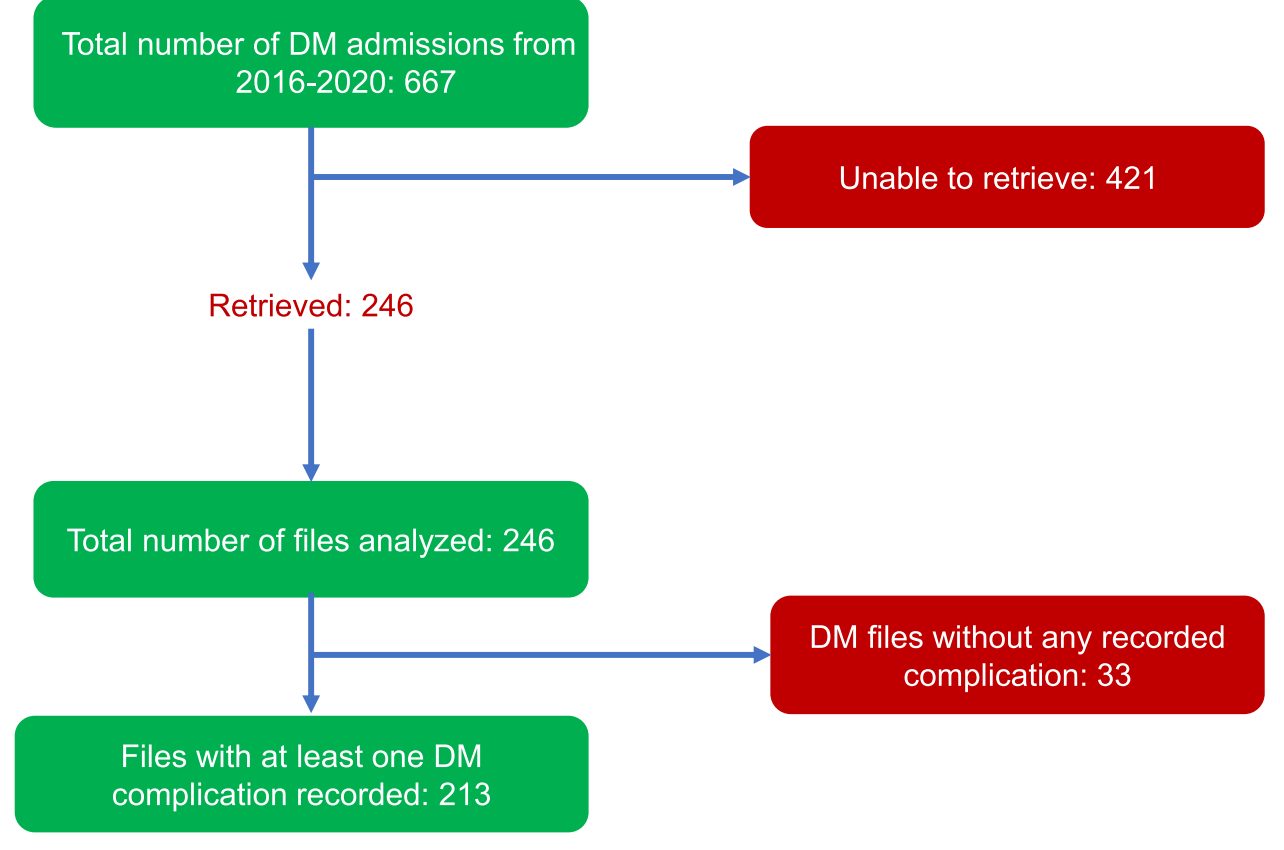

Figure I Study flow diagram showing the selection process.

summarized using means and standard deviations, medians and ranges. Bivariate analysis for association between exposure and outcome variables was assessed using Chi square or Fisher's exact test. Mann Whitney $U$-test was used to assess the significance of the observed mean for Age, duration of DM and HbAlc levels in the different variables. A $\mathrm{p}<0.05$ was considered statistically significant. Exposure variables with significant associations from bivariate analysis were fed into a multivariable logistic regression model and adjusted odds ratios computed.

\section{Ethics and Regulatory Approval}

This study was conducted in accordance with the ethical principles stated in the Declaration of Helsinki (1996) and applicable guidelines on Good Clinical Practice. Approval including waiver of consent was obtained from the Research and Ethics Committee of University Teaching Hospital of Kigali, Reference number: EC/CHUK/085/2021 while administrative clearance to access the archives was sought from the Hospital Administrator. Patient identifiers like names, registration numbers or initials were completely avoided throughout this article.

\section{Results}

Figure 1 shows how charts were retrieved during data collection process.

\section{Characteristics of Patients}

A total of 246 charts were reviewed. The median age was 56 years (IQR: $14-90,95 \% \mathrm{CI}=50.5-55.1$ ). Of the 246 participants, 135 (54.9\%) were females, 154 (84.6\%) Christians. Majority were from the Central region $(\mathrm{n}=138 ; 56.7 \%)$. Nearly half of participants belonged to National economic category $3(n=33 ; 52.4 \%)$. The rest of demographics are summarized in Table 1.

\section{Risk Factors of Diabetes Mellitus}

Of 246 total participants, participants who had records on risk factors included: alcohol intake status 167 (67.9\%), smoking 165 (67.1\%), BMI 82 (33.3\%), family history of DM 48 (19.5\%), duration of DM 213 (86.6\%), HbA1c levels 85 (34.6\%), and type of DM $181(73.6 \%)$ (Table 2). Out of those with recorded risk factors, $81(48.5 \%)$ had a recorded positive history of alcohol intake; $40(24.2 \%)$ were smokers. Forty-three $(52.4 \%)$ were obese and $27(56.3 \%)$ had a positive family history of DM.

Of all participants, 147 (69\%) had known their diagnosis for at least 6 years and majority $(n=153 ; 84.5 \%)$ had T2DM. Nearly all participants with complications $(n=81$; 95.2\%) had a poorly controlled HbAlc at the time of diagnosis of their complication. 
Table I Characteristics of Participants

\begin{tabular}{|c|c|}
\hline Variable, $N=246$ & Frequency, n (\%) \\
\hline Age & \\
\hline$<45$ years & $85(34.8)$ \\
\hline$\geq 45$ years & $159(65.2)$ \\
\hline Mean (SD) & $52.8(18.2)$ \\
\hline Sex & \\
\hline Female & $135(54.9)$ \\
\hline Male & $111(45.1)$ \\
\hline Marital status & \\
\hline Single & $5 I(2 \mid .8)$ \\
\hline Married & $137(58.6)$ \\
\hline Separated/Divorced & $7(3.0)$ \\
\hline Widowed & $39(16.7)$ \\
\hline Religion & \\
\hline Christians & $154(84.6)$ \\
\hline Muslims & $23(\mid 2.6)$ \\
\hline Others & $5(2.8)$ \\
\hline Residence & \\
\hline Central & | 38(58.7) \\
\hline Peripherals & $97(41.2)$ \\
\hline Insurance coverage & \\
\hline Insured & $217(91.6)$ \\
\hline Not Insured & $20(8.4)$ \\
\hline Occupation & \\
\hline Professionals & II (8.8) \\
\hline Non-Professionals & $1 \mid 3(9 \mid .1)$ \\
\hline Socioeconomic status & \\
\hline Category I & $10(15.9)$ \\
\hline Category 2 & $18(28.6)$ \\
\hline Category 3 & $33(52.4)$ \\
\hline Unclassified & $2(3.2)$ \\
\hline Alcohol & \\
\hline No & $86(51.5)$ \\
\hline Yes & $8 \mathrm{I}(48.5)$ \\
\hline Smoking & \\
\hline No & $125(75.8)$ \\
\hline Yes & $40(24.2)$ \\
\hline BMI & \\
\hline Obese & $43(52.4)$ \\
\hline Non-Obese & $39(47.5)$ \\
\hline Family history & \\
\hline No & $21(43.8)$ \\
\hline Yes & $27(56.3)$ \\
\hline
\end{tabular}

Abbreviations: $\mathrm{N}$, total number of entries; $\mathrm{n}$, number of entries in a given category; SD, standard deviation.
Table 2 Clinical Features of Participants

\begin{tabular}{|c|c|}
\hline Variable & Frequency, n (\%) \\
\hline \multicolumn{2}{|l|}{ Duration of $D M(N=2 \mid 3)$} \\
\hline$>6$ years & $66(31.0)$ \\
\hline$\leq 6$ years & $147(69.0)$ \\
\hline \multicolumn{2}{|l|}{ Type of DM $(N=|8|)$} \\
\hline TIDM & $28(15.5)$ \\
\hline T2DM & $153(84.5)$ \\
\hline \multicolumn{2}{|l|}{ Presenting symptoms $(\mathrm{N}=\mid 47)$} \\
\hline Asymptomatic & $4(2.7)$ \\
\hline Classical symptoms & $82(55.8)$ \\
\hline Non-classical symptoms & $6 I(4 I .5)$ \\
\hline \multicolumn{2}{|l|}{ Recent DM therapy $(\mathrm{N}=226)$} \\
\hline Combined orals & $27(12)$ \\
\hline Injectables & $164(72.6)$ \\
\hline Monotherapy & $35(15.5)$ \\
\hline \multicolumn{2}{|l|}{ Complications if any $(\mathrm{N}=246)$} \\
\hline No & $33(13.4)$ \\
\hline Yes & $213(86.6)$ \\
\hline Microvascular complications & $90(42.3)$ \\
\hline Macrovascular complications & $142(66.7)$ \\
\hline Acute complications & $67(31.5)$ \\
\hline \multicolumn{2}{|l|}{ HbAlc status $(N=104)$} \\
\hline Poorly controlled & $100(96.2)$ \\
\hline Well controlled & $4(3.9)$ \\
\hline \multicolumn{2}{|l|}{ Clinical outcome $(\mathrm{N}=|| 3)$} \\
\hline Alive & $74(65.5)$ \\
\hline Died & $39(34.5)$ \\
\hline \multicolumn{2}{|l|}{ Period of death $(\mathrm{N}=\mid 7)$} \\
\hline $1-5$ years & $4(23.5)$ \\
\hline$>5$ years & $13(76.5)$ \\
\hline
\end{tabular}

Abbreviations: $\mathrm{N}$, total number of entries in a given category; $\mathrm{n}$, number of entries in a given sub-category.

\section{Factors Associated with DM Complications}

At bivariate analysis (Table 3), duration of diagnosis $(\mathrm{P}=0.001)$ was significantly associated with $\mathrm{DM}$ complications. Age had a borderline significance of 0.053 .

At multivariate analysis (Table 4), patients 45 years or older were more likely to develop complications $(\mathrm{aOR}=6.2,95 \% \mathrm{CI}=1.4-27.6, \mathrm{p}=0.016)$ while those who take alcohol were 8 times more likely to develop complications $(\mathrm{aOR}=8,95 \% \mathrm{CI}=2-32.6, \mathrm{P}=0.003)$. T1DM were 
Table 3 Factors Associated with DM Complications

\begin{tabular}{|c|c|c|c|}
\hline \multirow[t]{2}{*}{ Variable } & \multicolumn{2}{|c|}{ Complication } & \multirow[t]{2}{*}{ p-value } \\
\hline & Yes, n (\%) & No, n (\%) & \\
\hline Overall & $213(86.5)$ & $33(13.4)$ & \\
\hline $\begin{array}{l}\text { Age } \\
<45 \text { years } \\
\geq 45 \text { years }\end{array}$ & $\begin{array}{l}69(81.2) \\
143(89.9)\end{array}$ & $\begin{array}{l}16(18.8) \\
16(10.1)\end{array}$ & 0.053 \\
\hline $\begin{array}{l}\text { Sex } \\
\text { Female } \\
\text { Male }\end{array}$ & $\begin{array}{l}114(84.4) \\
99(89.2)\end{array}$ & $\begin{array}{l}2 I(15.6) \\
12(10.8)\end{array}$ & 0.277 \\
\hline $\begin{array}{l}\text { Marital status } \\
\text { Married } \\
\text { Separated/Divorced } \\
\text { Single } \\
\text { Widowed }\end{array}$ & $\begin{array}{l}119(86.9) \\
6(85.7) \\
44(86.3) \\
33(84.6)\end{array}$ & $\begin{array}{l}18(13.1) \\
1(14.3) \\
7(13.7) \\
6(15.4)\end{array}$ & 0.971 \\
\hline $\begin{array}{l}\text { Religion } \\
\text { Christians } \\
\text { Muslims }\end{array}$ & $\begin{array}{l}139(87.4) \\
21(9 \mid .3)\end{array}$ & $\begin{array}{l}20(12.6) \\
2(8.7)\end{array}$ & 0.593 \\
\hline $\begin{array}{l}\text { Residence } \\
\text { Central } \\
\text { Peripheral }\end{array}$ & $\begin{array}{l}|2|(87.7) \\
83(85.6)\end{array}$ & $\begin{array}{l}17(12.3) \\
\mid 4(\mid 4.4)\end{array}$ & 0.461 \\
\hline $\begin{array}{l}\text { Insurance coverage } \\
\text { Insured } \\
\text { Not insured }\end{array}$ & $\begin{array}{l}187(86.2) \\
19(95)\end{array}$ & $\begin{array}{l}30(13.8) \\
\mathrm{I}(5)\end{array}$ & 0.480 \\
\hline $\begin{array}{l}\text { Occupation } \\
\text { Non-Professional } \\
\text { Profession }\end{array}$ & $\begin{array}{l}98(86.7) \\
10(90.9)\end{array}$ & $\begin{array}{l}\text { I5(I3.3) } \\
\mathrm{I}(9 . \mathrm{I})\end{array}$ & 0.693 \\
\hline $\begin{array}{l}\text { Economic status } \\
\text { Category } 1 \\
\text { Category } 2 \\
\text { Category } 3 \\
\text { Unclassified }\end{array}$ & $\begin{array}{l}10(100) \\
18(100) \\
32(97) \\
2(100)\end{array}$ & $\begin{array}{l}0(0) \\
0(0) \\
I(3) \\
0(0)\end{array}$ & 0.82 \\
\hline $\begin{array}{l}\text { Alcohol consumption } \\
\text { No } \\
\text { Yes }\end{array}$ & $\begin{array}{l}69(80.2) \\
73(90.1)\end{array}$ & $\begin{array}{l}17(19.8) \\
8(9.9)\end{array}$ & 0.073 \\
\hline $\begin{array}{l}\text { Smoking } \\
\text { No } \\
\text { Yes }\end{array}$ & $\begin{array}{l}103(82.4) \\
36(90)\end{array}$ & $\begin{array}{l}22(17.6) \\
4(10)\end{array}$ & 0.323 \\
\hline $\begin{array}{l}\text { BMI status } \\
\text { Non-Obese } \\
\text { Obese }\end{array}$ & $\begin{array}{l}31(79.5) \\
40(93)\end{array}$ & $\begin{array}{l}8(20.5) \\
3(7)\end{array}$ & 0.106 \\
\hline $\begin{array}{l}\text { Duration of DM } \\
>6 \text { years } \\
\leq 6 \text { years }\end{array}$ & $\begin{array}{l}64(97) \\
119(81)\end{array}$ & $\begin{array}{l}2(3) \\
28(19)\end{array}$ & 0.001 \\
\hline $\begin{array}{l}\text { Type of DM } \\
\text { TIDM } \\
\text { T2DM }\end{array}$ & $\begin{array}{l}5(83.3) \\
27(93.1)\end{array}$ & $\begin{array}{l}I(16.7) \\
2(6.9)\end{array}$ & 0.979 \\
\hline
\end{tabular}

Table 4 Multivariate Logistic Regression Analysis of the Factors Associated with DM Complications

\begin{tabular}{|l|c|c|}
\hline Variable & aOR (95\% CI) & p-value \\
\hline Age & Reference & \\
$<45$ years & $6.2(1.4-27.6)$ & 0.016 \\
\hline Sex years & & \\
Female & Reference & \\
Male & $0.5(0.1-1.8)$ & 0.285 \\
\hline Marital status & & \\
Single & Reference & \\
Married & $0.5(0.1-3.3)$ & 0.472 \\
Separated/Divorced & $0.2(0-3.5)$ & 0.255 \\
Widowed & $0.5(0-4.9)$ & 0.518 \\
\hline Residence & & \\
Central & Reference & \\
Peripheral & $0.3(0.1-1.1)$ & 0.060 \\
\hline Insurance coverage & & \\
Insured & Reference & \\
Not insured & $9.6(0.7-136.6)$ & 0.062 \\
\hline Alcohol consumption & & \\
No & Reference & \\
Yes & $8(2-32.6)$ & \\
\hline Duration of DM & & \\
$<6$ years & Reference & \\
$\geq 6$ years & $4.8(0.9-25.1)$ & \\
\hline Type of DM & & \\
T2DM & $14.1(1.2-161.5)$ & \\
TIDM & & \\
\hline Abbrevition & \\
\hline
\end{tabular}

Abbreviation: $95 \% \mathrm{Cl}, 95 \%$ confidence interval.

also more at risk of complications $(\mathrm{aOR}=14.1,95 \%$ $\mathrm{CI}=1.2-161.5, \mathrm{p}=0.034)$.

Hypertension $(\mathrm{n}=124,50.4 \%)$, Hyperglycemic state $(\mathrm{n}=59,24 \%), \mathrm{DN}(\mathrm{n}=58,23.6 \%)$, and stroke $(\mathrm{n}=38$, $15.4 \%)$ were the most commonly reported complications (Figure 2). Among the chronic complications, stroke had the lowest mean of $\mathrm{HbAlc}(8.5, \mathrm{SD}=2.1, \mathrm{p}=0.052)$ while DPN had the highest $(12.8, \mathrm{SD}=3.6, \mathrm{p}=0.344)$ (Table 5).

\section{Discussion}

Diabetes mellitus is a chronic illness and a significant cause of morbidity and mortality globally. It is estimated that 1.5 million people lose their lives to DM annually with majority of these deaths secondary to its complications. ${ }^{2}$ This contributes to significant disability 


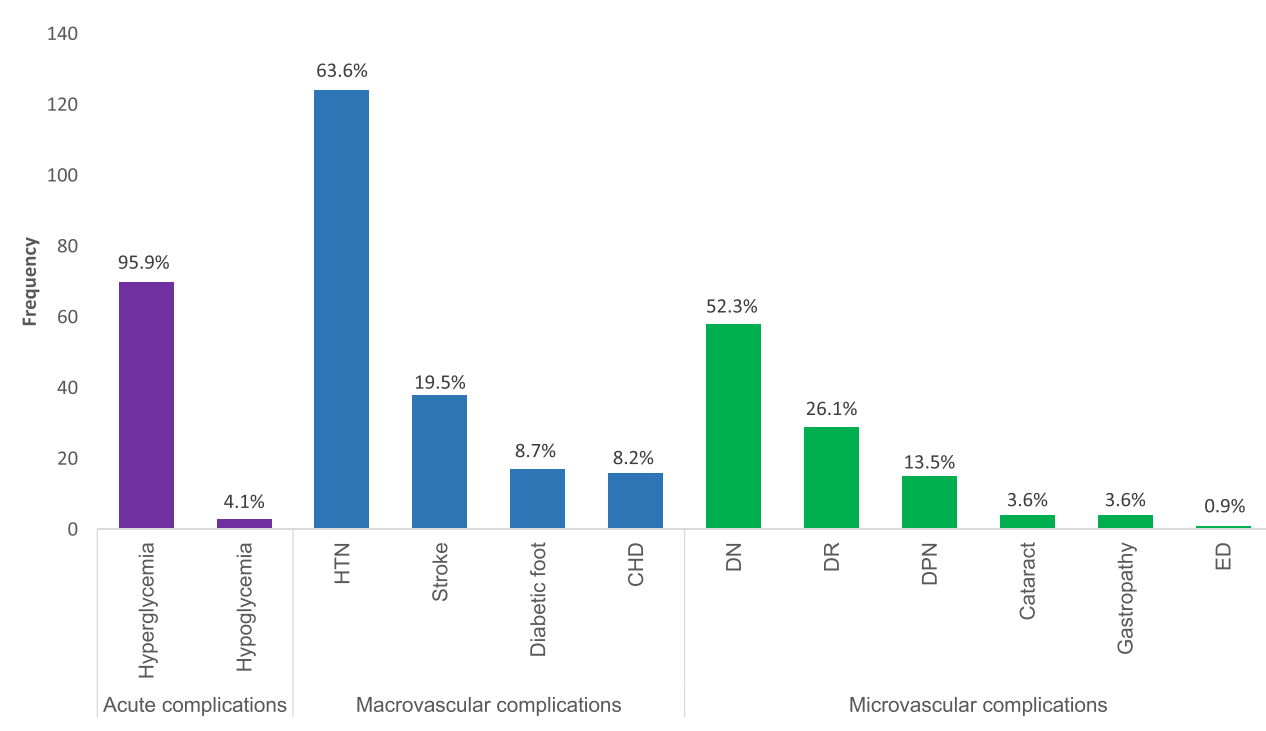

Figure 2 Complications of DM.

Abbreviations: HTN, hypertension; CHD, coronary heart disease; DN, diabetic nephropathy; DR, diabetic retinopathy; DPN, diabetic neuropathy; ED, erectile dysfunction.

adjusted life years (DALYs) especially in developing countries where health prioritization is still a challenge. In the current study, we found a high prevalence of DM complications. Stroke, neuropathy, hypertension and acute hyperglycemic states were prevalent with age, alcohol consumption, duration of DM, type of DM being the associated factors. Notably, at the time of diagnosis of complications, nearly all participants had evidence of poor glycemic control by HbA1c levels.

We found that majority of our participants were T2DM patients with a mean age of $52.8(\mathrm{SD}=18.2)$ years. This is similar to findings from most studies in Africa where T2DM is estimated to account for $75 \%$ of all cases. Although the mean age was slightly higher compared to findings from a previous study by Rudasingwa et al in the similar setting, this finding was rather not surprising given a generally reported rise in life expectancy in the country. ${ }^{16}$ Similar to their findings, older participants (more than 45 years) were more likely to develop complications a finding also supported by previous literature in other areas. For example, it was reported from a multi-country review that the more the advancement in age at diagnosis of DM, the more likely will the affected be at risk of complications and DM related deaths. ${ }^{17}$ Moreover, more than a third of participants in our study had succumbed to complications of DM. In addition to DM related morbidity, DM predisposes to several opportunistic infections such as pulmonary TB, candidiasis among others owing to its immune-depressive potential which contributes to the morbidity and mortality associated with DM. ${ }^{18,19}$ This translates in both individual and public expenditure in terms of the direct costs related to treatment as well as loss of productivity of the affected individuals. A study from Tanzania reported that treatment of DM complications took one of the main hospitals in Dar es Salaam $31 \%$ of its total outpatient costs, with an annual expenditure of at least $\$ 138$ per person representing 19 times more than the average. ${ }^{20}$ Additionally, it is a common finding in this era that interventions addressing communicable diseases such as in this case the Kir' ${ }^{\prime}{ }^{21}{ }^{21}$ are more technological and hence too sophisticated for use by the atrisk population which limits their uptake and possibly contribute the associated morbidity and mortality.

In our study, macrovascular complications were the most prevalent followed by microvascular and then acute complications. In the Rudasingwa study, microvascular complications were rather the most prevalent. The increasing burden of metabolic syndrome evidenced by the differences in hypertension in these two studies $(50.4 \%$ vs $31 \%$ respectively) could explain the observed differences in the prevalence of macro and microvascular complications over time. Other related studies have assessed the interaction between hypertension and T2DM both as a risk factor and a complication with overwhelming findings. ${ }^{15,22-24}$ Some epidemiological studies have reported that diabetic patients are twice as more likely to develop hypertension compared to non-diabetic individuals. ${ }^{25,26}$ Conversely, according to Yamazaki et al, hypertension is an important predisposing factor for macro-and micro-vascular complications and 
Table 5 Mean Age, Duration of DM and HbAlc as They Interact with DM Complications

\begin{tabular}{|c|c|c|c|c|c|c|}
\hline \multirow[t]{2}{*}{ Variable } & \multicolumn{2}{|c|}{ Age } & \multicolumn{2}{|c|}{ Duration of DM } & \multicolumn{2}{|c|}{ HbAlc Levels } \\
\hline & Mean (SD) & p-value & Mean (SD) & p-value & Mean (SD) & p-value \\
\hline Type of DM & & $<0.001$ & & 0.007 & & $<0.001$ \\
\hline Type I & $24.9(8.5)$ & & 2.I $(4.8)$ & & $15.6(2.9)$ & \\
\hline Type 2 & $57.1(15.6)$ & & $6.4(9)$ & & $10.8(3.4)$ & \\
\hline Duration of DM & & $<0.001$ & \multirow{3}{*}{\multicolumn{2}{|c|}{$\mathrm{N} / \mathrm{A}$}} & & 0.011 \\
\hline$>6$ years & $59.7(13.8)$ & & & & $9.9(3.1)$ & \\
\hline$\leq 6$ years & $48.6(19.1)$ & & & & $12.2(3.7)$ & \\
\hline Presence of Complications & & 0.111 & & 0.002 & \multirow{3}{*}{\multicolumn{2}{|c|}{$\mathrm{N} / \mathrm{A}$}} \\
\hline No & $48(18)$ & & $2.4(5.7)$ & & & \\
\hline Yes & $53.5(\mid 8.2)$ & & $6.7(8.8)$ & & & \\
\hline \multicolumn{7}{|l|}{ Type of complication } \\
\hline Microvascular & $56.8(15.6)$ & 0.02 & $9.9(9.8)$ & $<0.001$ & $10.3(3.4)$ & 0.02 \\
\hline Macrovascular & $59.1(15.7)$ & $<0.001$ & $8.8(9.3)$ & $<0.001$ & $10.5(3.5)$ & 0.002 \\
\hline Acute complications & $42.6(20.5)$ & $<0.001$ & $2.3(4.2)$ & $<0.001$ & 13.3(3.3) & $<0.001$ \\
\hline DPN & $56(14.1)$ & 0.621 & |4.4(9.5) & 0.002 & $12.8(3.6)$ & 0.344 \\
\hline DN & $57.2(14.4)$ & 0.067 & II.I(8.5) & $<0.001$ & $9.9(3.9)$ & 0.022 \\
\hline CAD & $61.6(14.7)$ & 0.135 & $\mid I .8(|| .2)$ & 0.016 & $10.7(3.3)$ & 0.662 \\
\hline DR & $58.3(15.9)$ & 0.145 & $9.1(11.3)$ & 0.389 & $10.2(1.9)$ & 0.362 \\
\hline CVD & $61.2(14.4)$ & 0.005 & $8.9(9.6)$ & 0.194 & $8.5(2.1)$ & 0.052 \\
\hline Diabetic foot & $65.9(10.3)$ & 0.007 & $10.1(9.9)$ & 0.194 & $11.9(3.8)$ & 0.715 \\
\hline Hypertension & $59.8(15)$ & $<0.001$ & $9(9)$ & $<0.001$ & $9.8(3)$ & $<0.001$ \\
\hline
\end{tabular}

Abbreviations: SD, standard deviation; DPN, diabetic peripheral neuropathy; DN, diabetic nephropathy; CAD, coronary artery disease; DR, diabetic retinopathy; CVD, cardiovascular disease.

patients who had hypertension were more likely to develop these complications early in the course. ${ }^{24} \mathrm{DM}$ complications and hypertension share similar pathogenic pathways involving common triggers including dyslipidemias, atherosclerosis, arterial remodeling and endothelial dysfunction which explains why they tend to occur in concert. ${ }^{22}$ The dilemma associated with management of the two comorbidities including possible drug interactions and toxicities cannot be over emphasized. This therefore, calls for coordinated interventions to break this interaction such as integrated routine blood glucose and blood pressure screening. The current study showed that DPN was occurring late in the course of DM contrary to similar studies which reported it as an earlier complication. Given that it was reported in the previous study as the most prevalent microvascular complication, this finding could mean that patients with DPN especially in our study setting present late, and quiet often prompted to do so by other related complications such as diabetic foot. This is further supported in part by the high levels of HbAlc observed with this complication. DR was also found to have a low mean age of reporting among our study population which is similar to findings from China $^{27}$ and Ethiopia. ${ }^{28}$

Hyperglycemic states including DKA and hyperosmolar hyperglycemic states (HHS) were by far more common compared to hypoglycemic states in our study. This finding is similar to the previous study which reported that up to $23 \%$ of participants had experienced at least one hyperglycemic state compared to $16 \%$ of those who reported hypoglycemia. DKA is the most prevalent diabetic emergency, by far the most common indication for hospital admissions among DM patients, and it is not uncommon for patients to present with DKA as the first feature. ${ }^{29}$ This is especially common among children and young adults in whom T1DM is prevalent, but it has been reported in adults as well. ${ }^{30}$ Although studies investigating complications of DM have hardly discussed DKA, it carries a significant risk for mortality with a single episode of 
DKA is estimated to have mortality rate of $5.2 \%$ which increases to $23.4 \%$ in those with recurrent DKA admissions according to Gibb et al. ${ }^{31}$ This could be even higher in resource limited settings where emergency care is lacking and reporting is still a common challenge. Social deprivation leading to stressful events, missing out on insulin therapy are some of the reasons that could explain the frequent occurrence of acute hyperglycemic states especially in resource limited settings.

Older participants, T1DM patients, those who reported a history of alcohol consumption and those who had DM for longer periods had more chances of developing complications. This is similar to study findings from Mexico which reported glycaemia, alcoholism, smoking habit and diet on legumes as predictors of DM complications. ${ }^{32}$ Though females were more in number, there was no statistical gender difference in relation to developmental of DM complications. Several related studies have discussed the role of alcohol consumption with diabetes mellitus with inconsistency. While many of these studies provide that alcohol may be a protective factor for development of $\mathrm{DM}$ and its complications, in its high concentrations it is undoubtedly a risk to serious DM complications. Alcohol alters lipid metabolism leading to elevated serum triglycerides, reduced levels of low-density lipoprotein (LDL) cholesterol, and elevated levels of high-density lipoprotein (HDL) cholesterol. ${ }^{33}$ Although there's reduced LDL, Lin et al reported a significant alteration in the biological function of alcoholics LDL which may accelerate the development of cardiovascular complications. Additionally, the levels of vitamin E which normally blunts the effect of LDL is reduced in alcoholic patients further predisposing to complications. ${ }^{34}$ With binge drinking, elevated triglycerides cause of pancreatitis which may lead to loss of beta cells in Islets of Langerhans and predispose the affected to hyperglycemic states. ${ }^{35}$ Therefore, regardless of the previous studies showing some level of protection against DM, targeted control programs should advocate for alcohol reduction especially among individuals living with DM.

Over $95 \%$ of the patients with complications had poor glycemic control (HbA1c $\geq 6.5 \%$ ). This implies that interventions aiming at achieving optimal glycemic control among DM patients such as behavioral modifications, adherence to treatment and home-based self-monitoring are either not well implemented or are insufficient since the current study still shows a higher burden of nephropathy, retinopathy, stroke and neuropathy among hospitalized patients. Population based qualitative studies need to be conducted to describe factors predisposing patients to poor glycemic control so as to guide on the appropriate interventions to control disease progression and the associated morbidity and mortality.

Type 1 diabetes is an autoimmune disease which results from progressive damage of beta cells in the Islets of Langerhans of the pancreas leading to significant reduction in the production of Insulin. With the exact cause of this derangement in the immune mediated damage not clearly understood, primary prevention of T1DM remains a mystical area of research. Type 2 diabetes on the contrary, is part of the continuum of metabolic syndrome. A number of risk factors interplay to give rise to this continuum including alcohol consumption, smoking, physical inactivity, unhealthy diet high in fat, obesity, and high blood pressure. In this study, alcohol consumption, high blood pressure and smoking were prevalent. In general, secondary prevention interventions include; 1) Patient self-care, 2) Home Blood glucose monitoring, and 3) Regular Glycosylated Hemoglobin estimations ideally at a 3-monthly interval. ${ }^{36-38}$

The influence of diet on weight, glycaemia, and glucose-insulin homeostasis has been studied as an effective mean of achieving glycemic control in diabetes, and to prevent cardiovascular complications. ${ }^{39}$ Despite this, nutrition remains one of the most difficult aspects of the management of T2DM due to challenges such as high costs of recommended diet, follow up and monitoring difficulty and lack of expertise especially in resource limited settings where nutritionists are scarce. ${ }^{40,41}$ In an open randomized trial in Rwanda, it was reported that there's a need for scaling up of self-monitoring blood glucose interventions for prevention of complications. ${ }^{36}$ These home glucose monitoring interventions when practiced well are associated with improved glycemic control and reduced longterm complications from diabetes. ${ }^{38}$

\section{Strength of the Study}

This study followed a previously conducted mixed prospective-retrospective study which reported on the patterns of DM complications among patients at CHUK 10 years prior to our study. Although based on a small population, our study answers the question of the impact of interventions that have been implemented to curb the morbidity and mortality of DM within the past decade and it draws its conclusions in regards to complications based on evidence provided by the biochemical tests such HbAlc unlike in the previous study. 


\section{Limitation of the Study}

Being a retrospective study, some of the outcome variables were subjectively classified based on assumptions. For example, hypertension was considered as a complication but without evidence whether it manifested or not after DM. Likewise, some conclusions could not be confidently drawn due to missing information in some patient charts.

\section{Conclusion}

Our study found a high prevalence of DM complications with most patients presenting with poor glycemic control. There was a notably significant association between DM and Hypertension. Alcohol consumption, advanced age, T1DM and duration of DM were the significant factors associated with development of complications. These findings should stimulate actions towards expansion of integrated services to lower-level health units to enable early detection of DM and hypertension. Public awareness to improve health seeking behaviors as well risk mitigating behavioral modifications need to be emphasized in low resource settings to reduce the burden of public health expenditure.

\section{Acknowledgment}

The study team would like to appreciate Mr. Emmanuel Munyaneza for the support during approval and data collection processes. We commend Ms. Germaine Uwiduhaye and Ms. Francine Mwitende for assisting us in Data collection. And to all that made great contribution towards this publication, we beg to submit our sincere thanks.

\section{Disclosure}

The authors report no conflicts of interest in this work.

\section{References}

1. Uloko AE, Musa BM, Ramalan MA, et al. Prevalence and risk factors for diabetes mellitus in Nigeria: a systematic review and meta-analysis. Diabetes Ther. 2018;9(3):1307-1316. doi:10.1007/s13300-0180441-1

2. Loke A. Diabetes [Internet]. WHO Update; 2021 [cited September 25, 2021]. Available from: https://www.who.int/news-room/fact-sheets/ detail/diabetes. Accessed December 3, 2021.

3. Bavuma CM, Musafiri S, Rutayisire PC, et al. Socio-demographic and clinical characteristics of diabetes mellitus in rural Rwanda: time to contextualize the interventions? A cross-sectional study. BMC Endocr Disord. 2020;20(1):1.

4. Tino S, Mayanja BN, Mubiru MC, et al. Original research: prevalence and factors associated with overweight and obesity among patients with type 2 diabetes mellitus in Uganda-a descriptive retrospective study. BMJ Open. 2020;10(11):e039258. doi:10.1136/bmjopen-2020039258
5. Asamoah-Boaheng M, Sarfo-Kantanka O, Tuffour AB, Eghan B, Mbanya JC. Prevalence and risk factors for diabetes mellitus among adults in Ghana: a systematic review and meta-analysis. Int Health. 2019;11(2):83-92. doi:10.1093/inthealth/ihy067

6. Mansour AA, Alibrahim NTY, Alidrisi HA. Prevalence and correlation of glycemic control achievement in patients with type 2 diabetes in Iraq: a retrospective analysis of a tertiary care database over a 9year period. Diabetes Metab Syndr. 2020;14(3):265-272. doi:10.1016/j.dsx.2020.03.008

7. Habumuremyi A, Mukiza J, Habimana S, Ngbolua KN, Niyigaba E, Bitunguhari $\mathrm{L}$. The prevalence of erectile dysfunction in male patients with diabetes mellitus (DM) in Rwanda: a cross-sectional study. Rwanda Med J. 2020;77(2):1-5.

8. Iglay K, Hannachi H, Joseph Howie P. et al. Prevalence and coprevalence of comorbidities among patients with type 2 diabetes mellitus. Curr Med Res Opin. 2016;32(7):1243-1252. doi:10.1185/ 03007995.2016.1168291

9. International Diabetes Federation. IDF Atlas 9th edition and other resources [Internet]. Diabetes Atlas; 2019 [cited October 3, 2021]. Available from: https://diabetesatlas.org/en/resources/. Accessed December 3, 2021.

10. Whiting DR, Guariguata L, Weil C, Shaw J. IDF Diabetes Atlas: global estimates of the prevalence of diabetes for 2011 and 2030 . Diabetes Res Clin Pract. 2011;94(3):311-321. doi:10.1016/j. diabres.2011.10.029

11. Gouda HN, Charlson F, Sorsdahl K, et al. Burden of non-communicable diseases in sub-Saharan Africa, 1990-2017: results from the Global Burden of Disease Study 2017. Lancet Glob Health. 2019;7 (10):e1375-87.

12. World Health Organisation. Rwanda [Internet]. 2016 [cited October 3, 2021]. Available from: https://www.who.int/diabetes/country-pro files/rwa en.pdf. Accessed December 3, 2021.

13. Pastakia SD, Pekny CR, Manyara SM, Fischer L. Diabetes in subSaharan Africa - from policy to practice to progress: targeting the existing gaps for future care for diabetes. Diabetes Metab Syndr Obes Targets Ther. 2017;10:247. doi:10.2147/DMSO.S126314

14. Kibirige D, Lumu W, Jones AG, Smeeth L, Hattersley AT, Nyirenda MJ. Understanding the manifestation of diabetes in sub Saharan Africa to inform therapeutic approaches and preventive strategies: a narrative review. Clin Diabetes Endocrinol. 2019;5(1):1-8. doi:10.1186/s40842-019-0077-8.

15. Mohan V, Seedat YK, Pradeepa R. The rising burden of diabetes and hypertension in Southeast Asian and African regions: need for effective strategies for prevention and control in primary health care settings. Int J Hypertens. 2013;2013:1-14. doi:10.1155/2013/409083

16. Rudasingwa GJ, Amendezo E, Twagirumukiza M. Clinical patterns and complications of African diabetic patients: preliminary data from Kigali University Teaching Hospital, Rwanda. African J Diabetes Med. 2012;20(2):1.

17. Nanayakkara N, Curtis AJ, Heritier S. et al. Impact of age at type 2 diabetes mellitus diagnosis on mortality and vascular complications: systematic review and meta-analyses. Diabetologia. 2021;64(2):275287. doi:10.1007/s00125-020-05319-w

18. Rodrigues CF, Rodrigues ME, Henriques M. Candida sp. infections in patients with diabetes mellitus. J Clin Med. 2019;8(1):76.

19. Berbudi A, Rahmadika N, Tjahjadi AI, Ruslami R. Type 2 diabetes and its impact on the immune system. Curr Diabetes Rev. 2020;16(5):442.

20. Grant P. Management of diabetes in resource-poor settings. Clinical Medicine [Internet]. 2013 Feb 1 [cited 2021 December 14];13(1):2731. Available from: https://www.rcpjournals.org/content/clinmedi cine/13/1/27. Accessed

21. Kabeza CB, Harst L, Schwarz PEH, Timpel P. Assessment of Rwandan diabetic patients' needs and expectations to develop their first diabetes self-management smartphone application (Kir'App). Ther Adv Endocrinol Metab. 2019;10:204201881984531. doi:10.1177/2042018819845318 
22. Petrie JR, Guzik TJ, Touyz RM. Diabetes, hypertension, and cardiovascular disease: clinical insights and vascular mechanisms. Can J Cardiol. 2018;34(5):575.

23. Price AJ, Crampin AC, Amberbir A, et al. Prevalence of obesity, hypertension, and diabetes, and cascade of care in sub-Saharan Africa: a cross-sectional, population-based study in rural and urban Malawi. Lancet Diabetes Endocrinol. 2018;6(3):208-222. doi:10.1016/S2213-8587(17)30432-1

24. Yamazaki D, Hitomi H, Nishiyama A. Hypertension with diabetes mellitus complications. Hypertens Res. 2018;41(3):147-156. doi:10.1038/s41440-017-0008-y

25. Gress TW, Nieto FJ, Shahar E, et al. Hypertension and antihypertensive therapy as risk factors for type 2 diabetes mellitus. Atherosclerosis Risk in Communities Study. $N$ Engl J Med. Internet 2000; 342(13):905-912.

26. Gress TW, Nieto FJ, Shahar E, et al. Diabetes, hypertension, and cardiovascular disease: an update. Hypertens. 2001;37(4):1053-1059. doi:10.1161/01.HYP.37.4.1053

27. Huang J-X, Liao Y-F, Li Y-M. Clinical features and microvascular complications risk factors of early-onset type 2 DIABETES MELlitus. Curr Med Sci. 2019;39(5):754-758. doi:10.1007/s11596-019-2102-7

28. Roba Debele G, Gosha Kanfe S, Birhanu Weldesenbet A, Mamo Ayana G, Wakene Jifar W, Beshir Raru T. Incidence of Diabetic retinopathy and its predictors among newly diagnosed type 1 and type 2 diabetic patients: a retrospective follow-up study at tertiary health-care setting of Ethiopia. 2021. doi:10.2147/DMSO.S300373

29. Rewers A, Dong F, Slover RH, Klingensmith GJ, Rewers M. Incidence of diabetic ketoacidosis at diagnosis of type 1 diabetes in Colorado youth, 1998-2012. JAMA. 2015;313(15):1570-1572. doi:10.1001/jama.2015.1414

30. Nadhem O, Nakhla E, Smalligan RD. Diabetic ketoacidosis as first presentation of latent autoimmune diabetes in adult. Case Rep Med. 2015;2015:1-3. doi:10.1155/2015/821397

31. Gibb FW, Teoh WL, Graham J, Lockman KA. Risk of death following admission to a UK hospital with diabetic ketoacidosis. Diabetologia. 2016;59(10):2082-2087. doi:10.1007/s00125-016-4034-0
32. Manuel Malacara J, Eugenia Dávalos L, Cervantes F, Castillo J, Velasco E. Risk factors of the complications of diabetes mellitus. Rev Invest Clin. 1991;43(1):3-9.

33. Emanuele NV, Swade TF, Emanuele MA. Consequences of alcohol use in diabetics. Alcohol Health Res World. 1998;22(3):211.

34. Lin RC, Dai J, Lumeng L, Zhang MY. Serum low density lipoprotein of alcoholic patients is chemically modified in vivo and induces apolipoprotein E synthesis by macrophages. J Clin Invest. 1995;95 (5):1979-1986.

35. Herreros-Villanueva M, Hijona E, Bañales JM, Cosme A, Bujanda L. Alcohol consumption on pancreatic diseases. World J Gastroenterol. 2013;19(5):638-647. doi:10.3748/wjg.v19.i5.638

36. Ng'ang'a L, Ngoga G, Dusabeyezu S, et al. Implementation of blood glucose self-monitoring among insulin-dependent patients with type 2 diabetes in three rural districts in Rwanda: 6 months open randomised controlled trial. BMJ Open. 2020;10(7):e036202.

37. Ng'ang'a L, Ngoga G, Dusabeyezu S, et al. Protocol: implementation of blood glucose self-monitoring among insulin-dependent patients with type 2 diabetes in three rural districts in Rwanda: 6 months open randomised controlled trial. BMJ Open. 2020:10(7); e036202.

38. Taylor JR, Campbell KM. Home monitoring of glucose and blood pressure. Am Fam Physician. 2007;76(2):255-260.

39. Forouhi NG, Misra A, Mohan V, Taylor R, Yancy W. Dietary and nutritional approaches for prevention and management of type 2 diabetes. BMJ. Internet. 2018;361. doi:10.1136/bmj.k2234

40. Miller V, Yusuf S, Chow CK, et al. Availability, affordability, and consumption of fruits and vegetables in 18 countries across income levels: findings from the Prospective Urban Rural Epidemiology (PURE) study. Lancet Glob Health. 2016;4(10):e695-703.

41. Kahan S, Manson JE. Nutrition counseling in clinical practice: How clinicians can do better. JAMA. 2017;318(12):1101-1102. doi:10.1001/jama.2017.10434

\section{Publish your work in this journal}

Diabetes, Metabolic Syndrome and Obesity: Targets and Therapy is an international, peer-reviewed open-access journal committed to the rapid publication of the latest laboratory and clinical findings in the fields of diabetes, metabolic syndrome and obesity research. Original research, review, case reports, hypothesis formation, expert opinion and commentaries are all considered for publication. The manuscript management system is completely online and includes a very quick and fair peer-review system, which is all easy to use. Visit http://www.dovepress.com/testimonials.php to read real quotes from published authors.

Submit your manuscript here: https://www.dovepress.com/diabetes-metabolic-syndrome-and-obesity-targets-and-therapy-journal 